\title{
In Defence of Historical \\ Constructivism about Races
}

\author{
E. DIAZ-LEON \\ University of Barcelona \\ University of Manitoba
}

\begin{abstract}
Social constructivism about races holds that races are socially real, that is, they are identical with socially constructed properties, or social kinds. One particular version of social constructivism, namely, historical constructivism, claims that the properties that make a group of people a race are certain historical properties of the individuals that belong to that group (e.g., the life histories of the members of the group, or their ancestors). Joshua Glasgow has recently argued, following Appiah, GoodingWilliams and others, that historical constructivism faces several problems. In particular, he argues, it faces a trilemma: either the characterization of races provided is circular, or, if it wants to avoid circularity, it will turn out to be either redundant or indeterminate. In this paper, my main aim is to explore this interesting challenge to historical constructivism about races, and argue that it can escape Glasgow's trilemma. I will focus on historical constructivism about races, but I hope my discussion will shed some light on the question of whether social constructivist accounts in general are tenable.
\end{abstract}

\section{Introduction: The Trilemma}

Social constructivism about races holds that races are socially real, that is, that races should be identified with socially constructed properties, or social kinds. In order to put forward a version of social constructivism about race, a theorist must hold that what makes a group of people a race is a class of social kinds that those individuals have in common. One particular version of social constructivism, namely, historical constructivism, claims that the properties that make a group of people a race are certain historical properties of the individuals that belong to that group (e.g., the life histories of the members of the group or their

Contact: E. Diaz-Leon <esadiazleon@gmail.com> 
ancestors). When these historical properties are understood as social properties, it is clear that this account of race counts as a version of social constructivism.

Joshua Glasgow (2010) has recently argued that historical constructivism faces one of several problems, that is, it faces the following trilemma: either the characterization of races provided is circular, or, if it wants to avoid circularity, it will turn out to be either redundant or indeterminate. In this paper, my main aim is to explore this interesting challenge to historical constructivism about races, and argue that it can escape Glasgow's trilemma. I will focus on historical constructivism about races, but I hope my discussion will shed some light on the question of whether social constructivist accounts in general are tenable.

The first part of Glasgow's critique of historical constructivism, namely, his argument for the claim that the historical constructivist characterization of race is circular, is a development of a similar objection put forward by $\mathrm{K}$. Anthony Appiah (1985). The basic idea behind Appiah's objection, as Glasgow explains it, is that according to historical constructivism, the only procedures for identifying races that historical constructivists could offer are circular. In particular, the argument goes, in order to identify some historical events as being those that make a group of people a race, we would first need a criterion for identifying such a group of people, and it seems that the only criterion we could use to identify such a group of people would be a racial criterion. As Appiah puts it, "sharing a common group history cannot be a criterion for being members of the same group, for we would have to be able to identify the group in order to identify its history" (1985: 27). Let's consider the following example: if we want to say that the historical event of the enforcement of racial segregation in the US is part of what makes the group of black people a racial group, we will need a (separate) criterion for identifying such a group of individuals whose life histories we want to use in order to explain what races are. The problem here seems to be that the only criterion we have for identifying the relevant groups, or the relevant life histories, is itself racial. For example, we could use the enforcement of racial segregation as a criterion for identifying members of the black race; but it seems that in order to identify the relevant individuals that satisfy the relevant historical property, namely, racial segregation, I need to appeal to a racial criterion again (i.e., the historical property at issue here seems to be the property of having been racially segregated, or segregated in virtue of their race). So, it seems that in order to identify the historical properties that will constitute races, I need to appeal to some independent racial criterion, what makes the account viciously circular.

Glasgow wants to defend a similar objection, but he makes clear that he is interested in the metaphysical reading of this objection, and not merely in the epistemological reading. The epistemological interpretation of the objection would be one according to which the main problem for historical constructivism is that it could not provide identifying procedures in order to be able to answer the ques- 
tion, 'how many races are there, and how can we find them out?' Glasgow argues, plausibly enough, that an account of the nature of races could be correct even if it makes it extremely hard for us to identify what groups turn out to be races.

However, he argues, it is possible to develop a metaphysical interpretation of the objection, according to which the problem is not just that historical constructivism cannot provide identifying procedures that are not circular, but rather that it cannot provide racial criteria that are not circular, that is, criteria that determine (in the constitutive sense) whether a certain group is a race or not. He puts the crucial objection as follows:

To launch this objection, we can start with the assumption ... that, in order for [events] $E_{1}$ and $E_{2}$ to be part of [racial group] $R_{1}$ 's distinctive history, they must be so by virtue of some property that they have in common. That is, there must be something in virtue of which $E_{1}$ and $E_{2}$ are distinctively assigned to the history of $R_{1}$. Let that common property be $g$, such that $E_{1}$ and $E_{2}$, and any other events distinctively assigned to $R 1$, are $g$. Historicalism must, then, tell us what it is for those events to be $g$. There are only two options: either $g$ is something racial, like part of the history of race $R_{1}$, or it is not. On the one hand, if $g$ is something racial, then historicalism is circular: it tells us that $R_{1}$ is a race only because its history includes $E_{1}$ and $E_{2}$, and $E_{1}$ and $E_{2}$ are part of its unique historical trajectory only because they are moments in the history of a race, $R_{1}$. (2010: 325)

This is then the first horn of the dilemma: according to Glasgow, historical constructivist accounts need to appeal to some properties in order to identify the groups of individuals whose life histories are going to constitute racial criteria. That is, if we want to identify racial group $\mathrm{R}_{1}$ with historical property $\mathrm{H}_{1}$, we need to determine first what $\mathrm{H}_{1}$ is (because if $\mathrm{H}_{1}$ is not a determinate property, then it cannot provide a racial criterion for constituting a determinate racial group). But it seems that in order to specify the nature of property $\mathrm{H}_{1}$, we need to appeal to some unifying property of the events that constitute $\mathrm{H}_{1}$, that is, we need a criterion for answering the question, 'why are events E1 and E2 both assigned to property Hi?' Why couldn't we appeal to some other events in the life histories of the same individuals, or even to some other individuals? One possibility, Glasgow argues, would be to appeal to some racial criterion: for instance, the reason that we appeal to the enforcement of racial segregation in the US, in order to identify the criteria that constitute races, is that this is a racial criterion, an event of racial significance. But this movement, Glasgow argues, is clearly circular. (We could avoid circularity by appealing to some criterion that is not 
racial, but this turn out to be problematic as well, according to Glasgow, as I will explain below.)

The first crucial question, then, is why historical constructivist accounts that appeal to historical events E1 and E2 in order to explain the nature of racial group $\mathrm{R}_{1}$, need to answer the question, 'in virtue of what do events $\mathrm{E}_{1}$ and $\mathrm{E}_{2}$ belong to the history of racial group RI, rather than some other racial group?' For instance, in virtue of what can we say that two specific instances of racial segregation in the US, such as two different individuals not being allowed to ride in certain train cars, belong to the same historical property $\mathrm{H} 1$ (i.e., racial segregation), which we want to identify with the racial group being black?

My basic answer is that, given our theoretical aims here, it is perfectly legitimate to answer this question in terms of property $\mathrm{H}_{1}$ itself, but this does not make the account viciously circular. Let me elaborate this point a bit more slowly. As I see it, the aim of historical constructivism is to provide racial criteria in order to explain what properties constitute the different racial groups. Their answer to this question is that certain historical properties determine what racial groups there are. Of course, if we want to spell out the details of the account, we will have to specify which particular historical properties determine which particular racial groups. For instance, it would be fair to ask what historical properties differentiate blacks from whites. In order to answer this question, we will need to appeal to a determinate, fully fleshed out historical property, such that we can answer, for any individual or any life history, whether it instantiates that property and therefore belongs to the racial group, or not. ${ }^{1}$ For instance, if we identify a history of racial segregation in the US with the black race, we could ask whether a certain individual or a certain event (e.g., someone not being allowed to ride in certain train car) counts as an instance of that historical property. But in order to answer this interesting question, we do not need to identify those individuals by means of a separate criterion: we have already identified what historical property corresponds to the racial group at issue, and we are just asking whether a particular individual or event falls under that historical property, and therefore under that racial group.

The more interesting theoretical project here is, of course, to specify what particular historical properties correspond to racial group R1. Imagine that we identify events $\mathrm{E}_{1}$ and $\mathrm{E}_{2}$ as being crucial in constituting racial group $\mathrm{R}_{1}$. It wouldn't make much sense, I contend, to ask at this point why events E1 and E2 are assigned to this historical property, or this racial group. The answer will be trivial: of course we are interested in events E1 and E2 because they both in-

1. Of course, it is always possible that our accounts of race appeal to criteria that are themselves vague, and have some borderline cases, but I do not think this would be a problem. I will ignore this complication in what follows. 
stantiate the relevant historical property $\mathrm{H}_{1}$, and this is why we appeal to them in order to explain what determines R1. To appeal to events E1 and E2, or to historical property $\mathrm{H}_{1}$, are just two sides of the same coin: they are just two ways of describing the very same account of race, the very same racial criteria, so I do not see any vicious circularity here.

\section{The Second Horn}

Let's now turn to the second horn of the dilemma (or, as we will see below, a trilemma). Glasgow agrees that it is possible to identify historical properties as race-making criteria in a non-circular way, but he argues, following Robert Gooding-Williams (1996), that this will then entail that those accounts are redundant, for the following reason:

Imagine, for example, that $g$ is just an event that involved people having visible profile $v$, where a visible profile is a certain set of biological traits that are detectable by the naked eye. That is, in this example, historicalists say that $R_{1}$ is a race because it has in its distinctive history $E_{1}$ and $E_{2}$, and that these events are part of $R I^{\prime}$ 's distinctive historical trajectory only because they are moments in the history of people who have visible profile $v$. Of such an account we should ask: why isn't simply having the visible profile itself what makes the race? Why isn't adding in history just an attempt to do an end-run around what appears to be the genuinely operative criterion for race, namely visible biological traits? And if the real criterion is visible traits, then historicalism is false. (2010: 326 )

The dilemma can then be formulated as follows: Glasgow argues that if a historical constructivist account appeals to some criterion $\mathrm{G}$ in order to explain in virtue of what the events E1 and E2 are distinctively assigned to the common history of a certain racial group $\mathrm{R}_{1}$, and this criterion $\mathrm{G}$ is itself racial, such as the property of involving people having visible profile $\mathrm{V}$ (associated with race Ri), then the account will be circular. And on the other hand, if $G$ is not itself a racial criterion, then we can identify $R_{1}$ with $G$ itself, and we do not need to rely on historical properties at all, which makes them redundant. Regarding the first horn of the dilemma, I agree that it would indeed be circular to claim that, say, black people are those that have certain life histories, where these life histories are identified in terms of those historical trajectories that individuals with the visible profile of black people typically instantiate. But, my point is, historical constructivism does not need to be formulated in those clearly circular terms. 
Glasgow agrees: it is possible to formulate the account so that it is no longer circular, but then, he argues, it wouldn't be a properly historical account any more. For instance, a non-circular version of the account could go as follows:

(HC1) Someone belongs to racial group $\mathrm{R}_{1}$ iff she has life history $\mathrm{H}_{1}$ in virtue of having visible profile $\mathrm{V}$.

This account is not circular because there is no racial criterion that appears explicitly in the right-hand side of the bi-conditional. And it would answer the crucial question 'why do events E1 and E2 belong to the life history $\mathrm{H}_{1}$ ?' as follows: in virtue of sharing the property 'being an event involving people having visible profile $V^{\prime}$. Glasgow agrees that this is not circular but as we have seen he would argue that this account is redundant: the specified property $\mathrm{H}_{1}$ is not playing any explanatory role because the property that is doing all the work in order to identify racial group $\mathrm{R}_{1}$ is the (biological) property of having visible profile $\mathrm{V}$, not the historical property.

In response, it is not clear to me why we should think that this account would be redundant: in my view, historical property $\mathrm{H}_{1}$ is playing a clear and distinctive explanatory role. We can see this point more clearly if we consider an alternative account which does not appeal to the historical property at all:

(HC2) Someone belongs to racial group R1 iff she has visible profile V.

I think it is clear that $\mathrm{HC}_{1}$ and $\mathrm{HC}_{2}$ are very different accounts of race. In particular, they would yield very different answers to the question, 'what groups of people are racial groups?' The accounts would certainly yield different extensions in different possible worlds: we can easily imagine a possible world $\mathrm{W}_{1}$ where people with visible profile $\mathrm{V}$ have very different life histories from the ones they typically have in the actual world, and in this way Ri would have different extensions, depending on whether we characterize it in terms of $\mathrm{HC}_{1}$ or $\mathrm{HC}_{2}$. In particular, if we appeal to $\mathrm{HC}_{2}$, $\mathrm{R}_{1}$ would have the same extension it has in the actual world, but if we appeal to $\mathrm{HC}_{1}, \mathrm{R}_{1}$ would have a very different extension: it would be empty, because by assumption no-one in $\mathrm{W}_{1}$ has life history $\mathrm{H}_{1}$ in virtue of having visible profile V. I agree that $\mathrm{HC}_{2}$ is not a historical account, but I fail to see why $\mathrm{HC}_{1}$ is not a legitimate historical account: it can answer the crucial question that Glasgow wants answered, and it can do it in a way that assigns a clear explanatory role to the historical properties invoked in the account, in order to distinguish it from the different account $\mathrm{HC}_{2}$.

To sum up my line of argument so far, Glasgow argues that historical constructivism faces a dilemma because it is either circular, or not historical at all. This dilemma was raised by the alleged necessity of specifying some criterion for 
choosing certain historical events rather than some others, in order to specify the historical property that we will identify with the corresponding racial groups. There are basically two ways of specifying such a criterion: either we appeal to racial criteria, or we don't. But if we appeal to racial criteria, then the account is clearly circular. And if we appeal to some (non-historical) non-racial criteria G, then the historical criteria are not playing any crucial explanatory role and we can just identify the corresponding racial group with the non-historical criteria G, which would make the account non-historical. Or so the argument goes. In response, we should of course accept that if we invoke some further racial criteria, the account will be circular, and if we invoke some non-racial, non-historical criteria only, the account will not be historical. But in my view - and as Glasgow points out, following Paul Taylor (2000) - this leaves some crucial option out: we could specify the criteria in terms of non-racial, but clearly historical properties, such as 'having such and such life histories'. Moreover, if we want to specify the account further, we will have to say which life histories fall under the account and which don't. But as far as I can see, it is perfectly OK to answer this question in terms of some further (non-historical) property, such as having a certain visible profile, because in this case what we are interested in is the historical property of having a certain life history in virtue of having a certain visible profile, which is very different from the non-historical property of having that visible profile simpliciter (but crucially, it is also different from other historical properties, such as having a certain life history in virtue of having a different visible profile, or some other feature). This specification of the relevant historical property does not make the account any less historical, in my view.

It could be argued at this point that even if $\mathrm{HC}_{1}$ is different from $\mathrm{HC}_{2}$, it is not clear why someone should favour $\mathrm{HC}_{1}$ over $\mathrm{HC}_{2}$. That is, any reasons one might have for endorsing $\mathrm{HC}_{1}$ would also be reasons for endorsing $\mathrm{HC}_{2}$, since they both claim that what unifies members of a certain race $\mathrm{R}_{\mathrm{I}}$ is a matter of having visible profile $\mathrm{V}$, and if so, why not go for $\mathrm{HC}_{2}$ directly, since it is simpler? Gooding-Williams makes a similar objection: "In other words, the successful use of this [common history] criterion will always presuppose that one has available some other criteria (or criterion) for determining whether the individuals in question are members of the same race" (1996: 42-3). That is to say, if we need a further, non-historical criterion in order to specify which kinds of historical properties we are going to identify with racial properties, rather than historical properties of a different kind, why shouldn't we just say that races are identical to that other non-historical criterion? Or in other words, as Glasgow puts it, if we need to answer the question of what makes those specific historical properties racially relevant as opposed to others, in terms of non-historical property G, then why shouldn't we just identify Ri with G? In my view the best response here is to emphasize that identifying $\mathrm{R}_{1}$ with a non-historical property, such as 
having visible profile $\mathrm{V}$, is very different from identifying $\mathrm{R} I$ with the historical property of having such and such shared histories in virtue of (or as a result of) having visible profile $\mathrm{V}$. These properties are different precisely because it is a contingent fact that individuals with visible profile $\mathrm{V}$ happened to have those shared histories. And according to this version of historicalism, being a member of a certain race is not a matter of having a certain visible profile, but rather a matter of having a certain history, as a result of having a certain visible profile. This is what races are (and what the term 'race' picks out).

One example of a historical account along these lines has recently been presented by Chike Jeffers (2013), who argues as follows:

Note that there is nothing circular or unsatisfyingly indeterminate about the sociohistorical account of race that I endorse here, because the claim is not merely that a race is a group that shares a common history but that ... a race is also a group linked by descent to a particular geographical region (sub-Saharan Africa, in the case of the black race). What makes the account sociohistorical rather than biological is the claim that it is only in the wake of enslavement and colonization by Europeans that the classification of these people as a group sharing physical characteristics (dark skin, curly hair, etc.) and place of origin (sub-Saharan Africa) resulted in a category of significance known as a "race." (419-20, fn. 51)

In my view, this account suggested by Jeffers is an example of the sort of partially historical account that I have in mind here. In this case, the historical property is identified in terms of some geographical properties of individuals, that is, the historical properties that we are interested in are those shared by subjects from certain geographical regions. In my example (HCI) above, I was focusing on some historical properties that subjects with certain visible profiles happened to have in common. In both cases, it is clear that these properties are historical properties in a substantial sense, even if the subjects who instantiate those properties also have other unifying properties. In addition, as Jeffers makes clear, it is the historical properties of these individuals, and not the geographical or biological ones (which they also instantiate, let's assume) that are race-making. ${ }^{2}$

2. To clarify, according to the version of historicalism that I am suggesting, races are to be identified with certain historical properties of a certain sort, say, the shared histories that people with a certain visible profile happened to have, or the shared histories that people with certain geographical origins happened to have. In my view, what makes these accounts of race sociohistorical is that race is identified with those sociohistorical properties themselves, rather than with the phenotypic properties, or the geographical properties. It could be argued that there is an alternative reading of Jeffers's passage above according to which what makes these accounts of race sociohistorical is that the concept of race is the result of certain sociohistorical factors. This reading would 
One final clarification: it might be argued that the real problem here for historical constructivism is that it is not clear what reasons someone might have to identify racial groups with historical properties. That is, someone might argue that any proposed account that aims to identify racial group Ri with historical property $\mathrm{H}_{1}$ will have to face the question, 'in virtue of what does property $\mathrm{H}_{1}$ determine racial group R1?' This is certainly an interesting question, but this is not so much a problem for the account, but rather a request for justification. Of course, any account that identifies property $P$ with property $G$ will have to say something in support of the claim that what determines that someone instantiates $P$ is really whether someone instantiates G. Philosophical claims are often of this form, and much can be said for or against them. An alternative way of asking the justificatory question would be: in virtue of what do G1 and G2 (which are two particular instances of $G$ ) instantiate P? In a sense, the answer to this question is trivial: they instantiate P because they instantiate G! In another sense, this question is very interesting: why should we think that instantiating $\mathrm{P}$ is a matter of instantiating G?

My point here, then, is that maybe we could understand Glasgow's question about why we should say that events E1 and E2 belong the life history H1, which historical constructivists use to explain the nature of racial group $\mathrm{R}_{1}$, along those lines. In a sense, this is a trivial question, and historicists are right to answer as follows: E1 and E2 belong to the same life history because they both instantiate Hi. In another sense, that question is very interesting and substantial, but as far as I can see it does not pose a problem for the characterization of the historical account: it is simply asking for the justification of this specific version of historical constructivism rather than another.

Compare: some biological realists about race characterize races in terms of reproductively isolated biological populations. A similar question might arise: why do individuals I1 and I2 belong to the same biological population? It could be argued that the account is circular, because it seems that the only reasonable answer to that question is that II and I 2 belong to the same biological population because they belong to the same racial population (or, if we want to avoid circularity, we should say that it is because they instantiate the same non-racial, non-biological property, which would make the account redundant). However, it seems clear that there is no genuine problem here for the account: this is just

be too weak in my view: as Haslanger (2003) argues, most of our concepts are the result of social and historical factors, so this is not a controversial claim about the concept of race in particular. At most, this claims amounts to a version of social constructionism about the concept of race (which is almost trivial, since most concepts are socially constructed in this way), but it clearly does not amount to a version of social constructionism about the property or kind being a member of a racial group, which is our main focus here. 
what the account says races are, that is, the account identifies racial populations with certain biological populations, and the only way of answering the question of why I1 and I2 belong to the same biological population is that this is the biological population that, according to our concept of race (or $\mathrm{R} I$ ), should be identified with races (or more in particular, $\mathrm{R}_{1}$ ). ${ }^{3}$

\section{The Third Horn}

Let's now turn to the third horn of the trilemma, that is, the only option that we have left, according to Glasgow, if we want to avoid both the circularity worry and the redundancy worry. We have already seen why, according to Glasgow, one way of avoiding circularity would make the account redundant: if we specify the historical events that constitute racial group $R_{1}$ as those that satisfy criterion $G$ (where $G$ is non-historical and non-racial), the account is not circular but becomes redundant because the property that is really doing the explanatory work here (in determining racial group RI) is G, not the corresponding historical events. I have already answered this objection by arguing that appeals to $G$ do not always have to make the historical events redundant, because they could just be a way of fully spelling out the specific historical property we are interested in (but it is true that in this case, property G would be at least partially historical, and therefore I agree with Glasgow that neither a racial criterion nor a non-racial but fully non-historical criterion will do). A second response, which I have also suggested above, is that maybe we should forget about the further criterion G, given that as I argued above, it is really not necessary: it is perfectly legitimate to formulate the constitutive racial criteria directly in purely historical terms, without the need for a further criterion $G$ underlying the historical events themselves. In any case, let's examine the third option for historical constructivism that Glasgow considers, and why it is not satisfactory on his view either.

3. It could be argued that there is a relevant disanalogy here, since in order to defend a biological account of races, one would need to identify races with properties that are biologically significant (i.e., of interest to biologists), whereas in order to defend a historical account of races one would just need to identify races with some historical properties, which do not have to be independently significant. However, it could be responded that in order for certain common histories of individuals to constitute historical properties properly speaking, we need to appeal to historical properties that are historically significant, that is, of interest to historians (or social scientists more in general). In my view, this is a more basic question than the one Glasgow focuses on. All parties to the debate about historicalism take for granted, I assume, that it is possible to give an account of what makes a certain historical trajectory a proper historical property, rather than just a collection of individual narratives. The question that Glasgow focuses on is not just what makes a certain historical trajectory historically significant, but rather (and assuming that there is an answer to that question), he is asking what makes a historical property racially significant. Thanks to an anonymous referee for pressing me on this issue. 
He poses the main challenge to historical constructivism as follows. First, he explains how a putative account of race could avoid both the circularity and the redundancy worries: "In these ways, historicalism can apparently evade the circularity objection by leaving all reference to race out of the pertinent historical moments, and it can avoid redundancy by virtue of making race truly a matter of what turn out to be shared historical trajectories" (2010: 328). This is exactly what I suggested above: let's define races just in terms of shared historical properties. What is the problem for this strategy, according to Glasgow? He adds,

But if $E_{1}$ and $E_{2}$ do not make essential reference to the history of the race ... then we need to ask how they are race-makers: by virtue of what are $E_{1}$ and $E_{2}$ the moments that separate $R_{1}$ from $R_{2}$ ? Here, I now want to argue, even the more sophisticated kinds of historicalism ... find fatal trouble with a third objection, the indeterminacy objection. If $E_{1}$ and $E_{2}$ do not either circularly smuggle in a reference to $R I$ or covertly piggyback on some nonhistorical $g$, then it seems that there won't be anything in virtue of which they, rather than some racially indistinct event $E_{3}$, are distinctively assigned to R1... . [The indeterminacy worry] is the problem that there is no sorting principle that assigns different historical moments to different races if historicalism is both noncircular and nonredundant. (2010: 328-9)

What is the main worry here? Glasgow further illustrates this objection by means of an example: imagine that we say that the event of certain individuals not being allowed to ride in certain train cars is part of what constitutes the black race. But, he claims, this event would happen at the same time as some other event, such as living during the second most recent appearance of Halley's Comet. If so, what makes it the case that the former property, but not the latter, is a racemaking property? Even assuming that everyone who instantiates the first property also instantiates the second property (at least in the actual world), it seems clear that we want to say that the property that determines someone's race is the former, not the latter. The problem, according to Glasgow, is that it is not clear what the historical constructivist could say in order to justify that claim, without appealing to some further criterion, which would then make the account either circular or redundant again. Perhaps the historical constructivist could say that it is just a brute fact that the former, but not the latter, is a race-maker (i.e., a racial criterion), but this would be clearly unsatisfactory, Glasgow maintains. More in particular, he argues that the main problem here is not just that in order to avoid both circularity and redundancy, historicalism will have to be indeterminate. The main worry is that it will be just false: he claims that we can clearly provide reasons for saying that having to ride Jim Crow is a racially significant prop- 
erty, as opposed to living during the second most recent appearance of Halley's Comet, which is clearly not race-making. According to Glasgow, the only version of historicalism that could solve the circularity worry and the redundancy worry at the same time would be such that it could not provide any answers to this further question, and this shows that historicalism is incorrect.

The solution to this apparent puzzle is the following: the reason we can appeal to the former property (i.e., riding Jim Crow) but not the latter in order to explain what makes the black people a race, is that according to historical constructivism, the concept of race (or the concept of black) just happens to refer to those historical properties rather than some others. That is, the term 'race' picks out historical properties of a certain sort, rather than others. According to some versions of historicalism, 'race' picks out certain historical properties shared by people with certain visible profiles. So, on this view, it is not a brute fact that the historical trajectories shared by people with a certain visible profile are racemaking. Or we could perhaps say that this is a brute fact about our concept of race: the term 'race' is associated with certain application conditions, of the form "common historical trajectories of people with such and such visible profiles", and the referents of 'race' will then be those groups that satisfy those descriptions, if any. We could call this a conceptual brute fact, but in my view there is nothing problematic here. This is just how concepts work. ${ }^{4}$

As we have seen, it is possible to formulate alternative versions of historicalism, for instance one according to which 'race' picks out certain historical properties shared by people with certain common geographical origins, and so on (or some combinations thereof). The main idea for our purposes here is that it is not a brute fact that, say, having to ride Jim Crow is a racially relevant historical property, rather than others, in any problematic sense of 'brute fact'. Rather, this is part of what a certain version of historicalism says about the nature of race. Of course this theory might be wrong at the end of the day. But it is just not the case, as far as I can see, that this theory cannot provide reasons for saying that that property is race-making, for it is part of the content of the theory that historical properties of such and such sort are race-making, and having to ride Jim Crow is a historical property of such sort.

Someone might insist that the historical constructivist needs to provide a justification for this claim. But this would not make historical constructivism different from any other account of race, or anything else for that matter: of course in order to defend an account of something in terms of something else, we should provide reasons in support of the identification. But I take it that the challenge to historical constructivism that Glasgow wants to put forward is of a

4. See Glasgow (2009) for a similar account of concepts and reference fixing in terms of the application conditions associated with our concepts. 
more fundamental sort than this: as I understand his line of argument, his main aim is to show that there is something especially problematic in the way historical constructivism is formulated, so that this theory is not able to provide racial criteria that are neither circular, nor redundant nor indeterminate. As I have tried to show, I think historical constructivism is a perfectly coherent contender regarding the nature of races, which can provide perfectly determinate historical properties (to the extent that historical properties are determinate), which are arguably identical with (or at least constitutive of) racial groups, in a way that is neither circular nor redundant. The important question, of course, is whether we have good, substantive reasons to endorse a historical account along these lines, rather than, say, a biological account of races, or a social constructivist account of another sort. But this is a topic for another occasion. ${ }^{5}$

\section{Conclusion}

To conclude, I would like to briefly discuss another response to the circularity objection to historical constructivism, presented by Jorge J.L. Gracia (2007), so as to compare it with the response I am suggesting here. Gracia's main aim is also to provide racial criteria that do not appear to be circular. In particular, he is interested in answering the sort of question that Glasgow focuses on, namely, what makes it the case that two historical events E1 and E2 belong to the same racial group rather than two different racial groups (or no racial groups whatsoever). He answers this challenge as follows: "At least three factors need to be considered: First, historical events that affect certain people directly and not others; second, the number of events - few isolated events cannot compare to chains or clusters of many events; and third, the significance of the events" (2007: 97). And he adds: "The three factors mentioned, when taken together, illustrate how certain historical events effectively tie some people, while at the same time separate them from others, thus rendering the group in question unique through the relations in which they are embedded and the properties that these relations generate" (98). The main idea here seems to be that there are some historical

5. A remaining worry, which is suggested in Glasgow's paragraph above, is that it is not clear whether historical constructivism wants to say that racial concepts refer to historical properties as a matter of conceptual analysis (or definition, so that the corresponding identifications would be analytic or a priori), or rather as a matter of a posteriori theoretical identifications. In my view, historical constructivism could be formulated in either way, and therefore objections that are addressed only against the a priori variety are not good objections against the a posteriori variety. Maybe we could understand Glasgow's objection here as an objection against the a priori version, but then it is clear that the a posteriori version of historical constructivism could easily escape this problem, because on this version identifications of the form "R $\mathrm{R}_{1} \mathrm{H}_{1}$ " are not analytic truths, but rather a posteriori identities. 
events, or some historically demarcated groups of people, that for some reason are more suitable for being identified with racial groups than others. That is, some historical properties effectively tie some people whereas other historical properties do not tie their subjects to a sufficient degree. In my view, it is not clear that this is a satisfactory answer to the challenge, because it is not clear why some historical events effectively tie some people together to a sufficient degree, and therefore can constitute racial groups, and some do not. For example, what determines that two historical events E1 and E2 are part of the same racial group rather than two different groups, on this account? Those two historical events, we can assume, affect people directly, and can be part of clusters of many events, and can be very significant, but it is not clear how these three factors "effectively tie some people". In other words, it is not clear that there is something intrinsic about these events that is tying those events or those individuals together, independently of the fact that we have decided to group those events together under the same label or concept. That is to say, what is missing from this answer is exactly the conceptual answer I was rehearsing above, namely, that the best answer to the question of why historical events E1 and E2 belong to the same racial population rather than two different racial populations is that according to our concept of race, the historical properties that are to be identified with races in general (or with a particular race in particular) are historical properties of such and such sort, and in addition, that events E1 and E2 fall under the same historical property of that sort.

In addition, Gracia also argues that in order to avoid the circularity worry, we should not appeal to historical events that follow the constitution of race, only to those that precede it, or those within which a race is constituted. He explains:

It certainly makes sense to argue that a race could not be individuated by the history that follows the constitution of the race, for that history presupposes the race. However, the history that is regarded as individuating in the Familial-Historical View need not be this history, but rather it can be the history that precedes the constitution of the race or even the history within which the race develops. The history that precedes a race is not contingent on the race and can be described without reference to it, so the problem of Circularity does not arise concerning it. (2007: 91)

In my view, these considerations are neither here nor there: it does not matter in general whether the historical events that we appeal to in order to formulate historical constructivism precede the race, or follow its constitution, or are those within which the race develops. That is, it does not matter for the general 
purpose of defending historicalism from the circularity/redundancy objection. In principle, one could formulate versions of historicalism in terms of any of those historical events. For instance, we could formulate an account of the racial groups that are nowadays instantiated just in terms of historical properties of our ancestors. In addition, we could formulate an account of the racial groups that were instantiated at some point in the past $\mathrm{T}_{1}$ just in terms of historical properties that followed $\mathrm{T}_{1}$, such as the historical properties of those individuals and their descendants. In my view, what really provides an answer to the circularity/redundancy worry is the conceptual point that I rehearsed above, namely, that if we want to provide an account of what features of the world are racemaking, and our answer turns to be 'historical properties of such and such type', and more in particular, we identify racial group Ri with historical property $\mathrm{H}_{1}$, under which both historical events E1 and E2 fall, then the answer to the question of what unifies events E1 and E2 and why they are both assigned to racial group $\mathrm{R}_{1}$ is very easy: because $\mathrm{E}_{1}$ and $\mathrm{E}_{2}$ both instantiate the historical property $\mathrm{H} 1$, which as a matter of conceptual analysis (or a posteriori theoretical identification) is the property that corresponds to the racial concept $\mathrm{R}_{1}$.

\section{Acknowledgements}

I am grateful to the Social Sciences and Humanities Research Council of Canada for financial support. I presented this paper at the I GRSelona Conference and the LOGOS Seminar at the University of Barcelona. I am very grateful to the audiences for very helpful feedback. Extra thanks are due to Tyler Doggett, Sally Haslanger, Meena Krishnamurthy, Dan López de Sa, and very especially Joshua Glasgow, for very useful comments and discussion. I also wish to thank several anonymous reviewers for very helpful comments.

\section{References}

Appiah, K. Anthony (1985). The Uncompleted Argument: Du Bois and the Illusion of Race. Critical Inquiry, 12(1), 21-37.

Glasgow, Joshua (2009). A Theory of Race. Routledge.

Glasgow, Joshua (2010). The End of Historical Constructivism: Circularity, Redundancy, Indeterminacy. The Monist, 93(2), 321-35.

Gooding-Williams, Robert (1996). Outlaw, Appiah, and Du Bois's “The Conservation of Races". In Bernard W. Bell, Emily R. Grosholz, and James B. Steward (Eds.), W.E.B. $\mathrm{Du}$ Bois on Race \& Culture (39-56). Routledge 
Gracia, Jorge J.L. (2007). Individuation of Racial and Ethnic Groups: The Problems of Circularity and Demarcation. In Jorge J.L. Gracia (Ed.), Race or Ethnicity? On Black and Latino Identity (78-100). Cornell University Press

Haslanger, Sally (2003). Social Construction: The "Debunking" Project. In Frederick Schmitt (Ed.), Socializing Metaphysics (301-25). Rowman \& Littlefield

Jeffers, Chike (2013). The Cultural Theory of Race: Yet Another Look at Du Bois's "The Conservation of Races". Ethics, 123(3), 403-26.

Taylor, Paul (2000). Appiah's Uncompleted Argument: W.E.B. Du Bois and the Reality of Race. Social Theory and Practice, 26(1), 103-28. 